\title{
Prevalence of Musculoskeletal Pain in Bio-Pharmaceutical Industry Workers
}

\author{
Dhairav Alkesh Shah ${ }^{1}$, Nirati Paresh Lakhani \\ ${ }^{1}$ Head Physiotherapist, Asiya Physiotherapy and Rehabilitation Clinic, Mumbai \\ ${ }^{2}$ Intern, P.T. School and Center, Seth GS Medical College and KEM Hospital, Mumbai \\ Corresponding Author: Dhairav Alkesh Shah
}

\begin{abstract}
The purpose of this study was to identify the prevalence of musculoskeletal problems in biopharmaceutical industry workers. A cross sectional survey was conducted on 33 bio-pharmaceutical industry workers by administering the Extended Nordic Musculoskeletal Questionnaire to quantify the musculoskeletal pain and activity limitation in 9 body regions. The Rapid Office Strain Assessment was used to assess the work-related postures and ergonomics of the computer operators in this industry. A Self-Designed Questionnaire was administered to obtain data regarding the various musculoskeletal problems faced by Bio-pharmaceutical industrial workers, work-related risk factors and various postures attained throughout the day.

Out of the 33 workers investigated, 21 workers $(63 \%)$ of the workers experienced musculoskeletal pain. Isolated spine pain was the commonest, and was reported in 8 out of 21 individuals (38\%). Spine with upper and lower limb pain was the next most common, and was reported in 5 out of 21 individuals (24\%). 4 out of 21 individuals had spine and lower limb pain (19\%). The Rapid Office Strain Assessment scores of all the workers were above 5 indicating "high risk" which implied that immediate ergonomic change was necessary. This study concluded that there was $63 \%$ prevalence of musculoskeletal pain. The most common site of pain was the spine, followed by pain in the spine with both upper and lower extremities. All the workers were exposed to different ergonomic risk factors. The study concluded that implementation of ergonomic interventions may minimize the risks of work related musculoskeletal pain.
\end{abstract}

Keywords: Work-related musculoskeletal disorders, Extended Nordic Musculoskeletal Questionnaire, Rapid Office Strain Assessment, Ergonomic hazards

\section{INTRODUCTION}

Work-related

musculoskeletal disorders are responsible for morbidities in many working populations. Apart from lowering the quality of workers' life and reducing productivity, they are the most expensive form of work disability. In India, estimates have shown that these disorders contribute to about $40 \%$ of all costs toward the treatment of work-related injuries. These disorders are also reported to cause lost work time or absenteeism, increased work restriction, transfer to another job, or disability than any other group of diseases with a considerable economic toll on the individual, the organization and the society as a whole. These disorders are considered to be multifactorial, that are caused due to the interactions between various risk factors, which result in conditions that vary across different occupations. Findings of scientific research have identified physical, psychosocial/organizational, and individual occupational risk factors for the development of this group of disorders. ${ }^{[1]}$ Various studies have been done to find the prevalence of these disorders. The global prevalence of occupation related 
musculoskeletal disorders ranges from $14 \%$ - 42\%. In India, epidemiological studies indicate the community-based prevalence of about $20 \%$ and occupation-specific prevalence found to be as high as $90 \%$ in various studies. ${ }^{[2]} 55.8 \%$ of the bus drivers experienced these disorders in a study in Karnataka. ${ }^{[3]} 62.5 \%$ of the workers were prone to work related injuries in a textile industry in Tamil Nadu. ${ }^{[4]}$

The most commonly reported biomechanical risk factors with at least reasonable evidence include excessive repetition, awkward postures, and heavy lifting. ${ }^{[2] ~ P r o l o n g e d ~ w a l k i n g, ~ r u n n i n g, ~}$ repetitive tasks such as lifting, carrying, pulling, and pushing of heavy loads are required in an industry. Pulling/pushing containers and lifting/carrying loads lead to repetitive bending, awkward postures, static muscle contraction, and as a result have a high risk of musculoskeletal disorders. ${ }^{[3]}$ Both experimental science and epidemiology indicate that job features that increase the risk of work related musculoskeletal disorders are heavy lifting, repetitive hand motions, and static work in a fixed posture, vibrations and any of these in combination along with an undesirable psychosocial work environment. Other risk factors that have been acknowledged are manual handling, frequent bending and twisting, heavy physical work and body vibration. ${ }^{[5]}$

The World Health Organization (WHO) defines musculoskeletal disorders as "multifactorial, with work contributing significantly, though not exclusively, to causing the disease." Work-related musculoskeletal disorders can result from or be worsened by recurrent, vigorous, or prolonged work activities with inadequate recuperation. ${ }^{[6]}$

In pharmaceutical industry, where pharmaceutics are packed, workers are involved in a fairly long hour of static work. In packing works, awkward posture and repetitive movements are very common. The majority of jobs are characterized by a sitting posture worker's head and trunk flexed forward and shoulders flexed and abducted. (Ramazan Mirzaei et al., 2014)

In pharmaceutical industry, where pharmaceutics are packed, workers are involved in a fairly long hour of static work. In packing works, awkward posture and repetitive movements are very common. The majority of jobs are characterized by a sitting posture worker's head and trunk flexed forward and shoulders flexed and abducted. (Ramazan Mirzaei et al., 2014)

In pharmaceutical industry, where pharmaceutics are packed, workers are involved in a fairly long hour of static work. In packing works, awkward posture and repetitive movements are very common. The majority of jobs are characterized by a sitting posture worker's head and trunk flexed forward and shoulders flexed and abducted. (Ramazan Mirzaei et al., 2014)

In pharmaceutical industry, where pharmaceutics are packed, workers are involved in fairly long hours of static work. In packing jobs, awkward posture and repetitive movements are very common. The majority of jobs are characterized by a sitting posture, in which the worker's head and trunk are flexed forward and shoulders flexed and abducted, according to Ramazan Mirzaei et al. Prevalence of work related musculoskeletal diorders in pharmaceutical factory workers in Dehradun was high. Lower back, shoulder and wrists/hand and neck complaints were found respectively high. ${ }^{[7]}$ This study was performed at a Biopharmaceutical industry which manufactured various products such as tubing, sterile connectors, clean room disinfectants and gowns, crimped silicone and PFTE hoses, filters, laboratory instruments, single use assemblies, RFID tags and area monitoring systems. This Biopharmaceutical industry had various departments, including Warehouse, Manufacturing Department and an Office. All these departments had separate Job demands, and hence had separate risk factors of the work-related musculoskeletal disorders. 
The office staffs were computer operators, and were typically vulnerable to awkward and static sitting postures, as well as prolonged hours of sitting. The warehouse staff had the job demands of prolonged standing on hard surfaces, and the strenuous physical demand of loading and unloading which caused a predisposition to risk factors of lifting, carrying, pushing and pulling. These staff also had to work with a cutting machine and a heat shrinking machine. Due to working in confined spaces, repetitive bending and twisting occurred, which was another risk factor. ${ }^{[8]}$

The staff of the Manufacturing Department worked with a Sealing machine and also did other housekeeping work such as dusting and mopping. This machine also created localized segmental vibrations which increased the risk of developing Hand-arm vibration syndrome. This syndrome is a collection of sensory, vascular, and musculoskeletal symptoms caused by repetitive trauma from vibration. One hypothesis for the relationship of this syndrome and arterial thrombosis, is that vibration-induced shear stress damage the vascular endothelium which leads to activation of the coagulation cascade. ${ }^{[9]}$

Musculoskeletal disorders affect the muscles, nerves, blood vessels, ligaments and tendons. Workers in many different industries and occupations can be exposed to risk factors at work, such as lifting heavy items, bending, reaching overhead, pushing and pulling heavy loads, working in awkward body postures and performing the same or similar tasks repetitively. Exposure to these known risk factors increases a worker's risk of injury. ${ }^{[10]}$ Such disorders are also known as cumulative trauma disorders, repetitive strain injuries and overuse injuries. ${ }^{[11]}$

Borhany et al (2018) reported that headache and back pain were most common in computer users. ${ }^{[12]}$ Research shows evidence for a causal relationship between computer work and wrist tendonitis, forearm disorders, tension neck syndrome, shoulder tendonitis and epicondylitis.

Musculoskeletal disorders are the most common causes of long-term sick-leave and disability pension in several industrial countries. ${ }^{[14]}$

Various measures have been created for assessment of physical workloads, such as the Rapid Upper Limb Assessment (RULA), the Rapid Entire Body Assessment (REBA), the Strain Index (SI), the Occupational Repetitive Actions Checklist (OCRA) and the Threshold Limit Value for Hand Activity. ${ }^{[8]}$ This study uses two assessment tools: The Nordic Musculoskeletal Questionnaire and the Rapid Office Strain Assessment. The Nordic Musculoskeletal Questionnaire (NMQ), a standardized screening and surveillance tool was used to find out the body regions affected by musculoskeletal symptoms. ${ }^{[15]}$ Musculoskeletal complaints of different parts of the body (lower back, neck, shoulders, hands/wrists, hips/thighs, and ankles or feet) in the past 12 months were ascertained with the standardized Nordic Musculoskeletal questionnaire. It was presented to participants with anatomic diagrams that highlighted each part of the body for clarity. If symptoms were present, participants were asked to answer additional questions regarding the duration of these symptoms (to indicate whether these symptoms were present in the past seven days), whether it had affected their work activities, and to note whether they had seen a doctor or physiotherapist regarding their symptoms.

The NMQ has been applied to a wide range of occupational groups to evaluate musculoskeletal problems, including computer and call center workers, car drivers, coopers in the whisky industry, nursing and forestry workers. The reliability of the NMQ, using a test-retest methodology, found the number of different answers ranged from 0 to $23 \%$. Validity tested against clinical history and the NMQ found a range of 0 to $20 \%$ disagreement. The authors concluded this was acceptable in a screening tool. Comparing pain in the 
last 7 days and clinical examination found sensitivity ranged between 66 and $92 \%$ and specificity between 71 and $88 \%$. This study concludes that the NMQ is repeatable, sensitive and useful as a screening and surveillance tool. However, medical examination is essential to establish a clinical diagnosis. ${ }^{[15]}$

The second screening tool used in this study was the Rapid Office Strain Assessment (ROSA) which was used in assessing the work-related postures and ergonomics in the computer operators of this industry. ROSA is based on the Canadian Standards Association (CSA) International (2000) CSA-Z412: Guideline on office ergonomics. It highlights risk factors identified through extensive research specific to office and computer work. The risk factors incorporated into the tool are organized into several subsections: chair, monitor and telephone, and mouse and keyboard. These subsections highlight the risk factors unique to each component of the office workstation, and weigh risk scores based on the CSA-Z412. The scores recorded in each subsection are then combined to achieve a ROSA final score, indicative of the overall risk of musculoskeletal discomfort, as a result of the configuration of the office. ${ }^{[16]}$

The ROSA was designed to quickly quantify risks associated with computer work and to establish an action level for change based on reports of worker discomfort. ROSA final scores exhibited high inter- and intra-observer reliability (ICCs of 0.88 and 0.91 , respectively). Risk factors related to musculoskeletal disorders in office work include sustained non-neutral postures of the upper limbs, prolonged static sitting while using the computer, awkward postures of the head and neck, and increased muscular activity in the upper back and shoulders. Research by Sonne et al. found a significant relationship between workerreported discomfort and ROSA final scores. A ROSA final score of 5 might therefore be useful as an action level indicating when immediate change is necessary. ROSA proved to be an effective and reliable method for identifying computer use risk factors related to discomfort. ${ }^{[16]}$

\section{Purpose and need of study:}

There is a paucity of studies on the musculoskeletal problems faced by biopharmaceutical industry workers in India. Thus, the purpose of this study was to find the prevalence of musculoskeletal problems in bio-pharmaceutical industry workers. The study also aims to complement the knowledge of the severity of work related disorders with the purpose that the information may be useful for developing viable strategies towards minimizing industrial injuries. The bio-pharmaceutical industry workers would usually fail to implement ergonomics in their activities which may lead to damaging physiological changes that can lead to pain. If regularly occurring pain or discomfort is ignored, the physiological damage can lead to injury. Application of the ROSA assessment in various industries could be used as a twopronged intervention strategy for the primary prevention of work related musculoskeletal disorders: Changes at the management level in the form of workplace redesign, as well as teaching the employees behavioral changes.

\section{Aims and objectives of this study:}

- To understand the prevalence of musculoskeletal pain assessed by the Nordic Musculoskeletal pain questionnaire in individuals working in the Bio-pharmaceutical industry

- To identify the commonest site of pain and understand the various risk-factors and causes for the same

- To understand the prevalence of incorrect ergonomics in computer operators in this industry using the ROSA (Rapid Office Strain Assessment)

- To correlate the prevalence of pain with the ROSA (Rapid Office Strain Assessment) scores to understand the effect of poor ergonomic practices on pain 


\section{MATERIALS AND METHODS}

A cross-sectional study was carried out on bio-pharmaceutical industrial workers in the age group of 20-60 years. The Informed Consent Document was signed by every volunteer. The study was conducted by administering a Self-Designed Questionnaire aimed at getting information regarding the various musculoskeletal problems faced by Bio-pharmaceutical industrial workers, work-related risk factors and various postures attained throughout the day.

\section{Inclusion criteria:}

1. All employees from all departments office staff, warehouse and manufacturing departments

2. Both male and female employees of all age groups

\section{Exclusion criteria:}

1. Non-musculoskeletal causes of pain (migraine, hernias etc.)

2. Past orthopedic surgeries

3. Use of assistive devices

4. Osteoporosis or systemic conditions (Tumors \& Rheumatologic disease)

5. Congenital anomalies

6. Recent Fractures

\section{RESULTS}

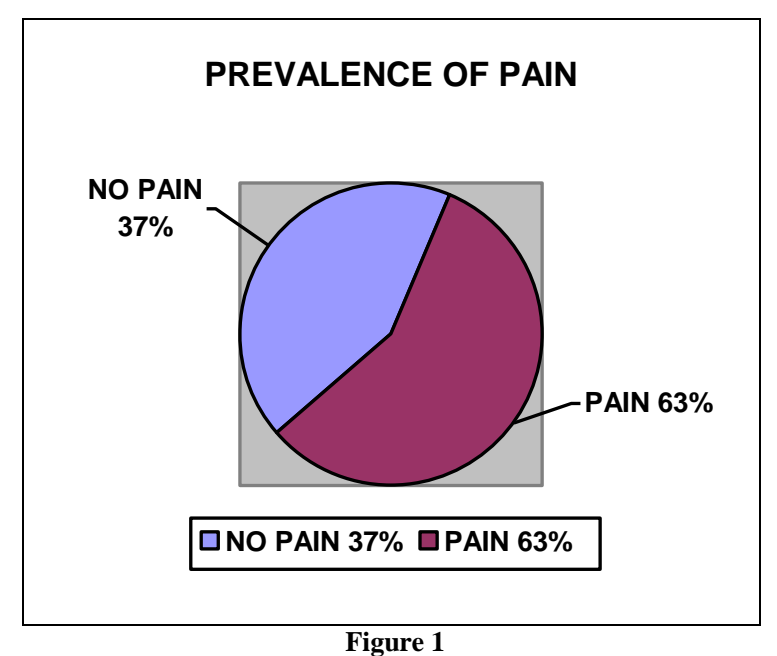

\section{INFERENCE:}

Out of the 33 workers, 21 workers $(63 \%)$ of the workers experienced musculoskeletal pain.

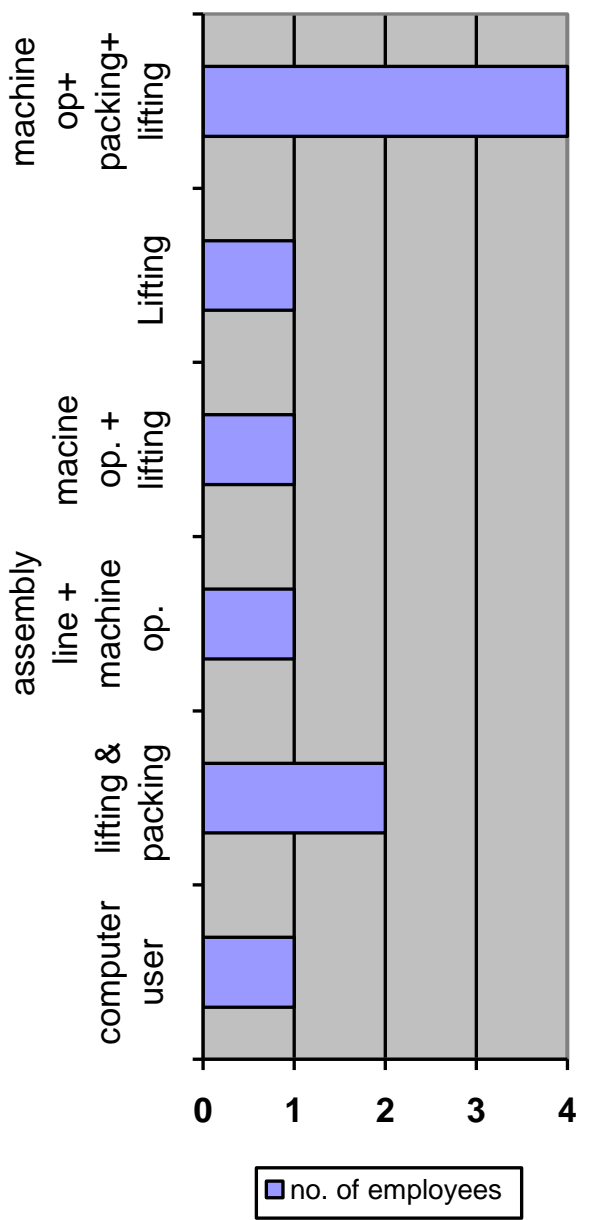

Figure 2: Occupation of Workers in the Warehouse

\section{INFERENCE:}

Out of the total 33 workers, 9 workers $(27 \%)$ were employed in the Warehouse.

Out of these $27 \%$ warehouse staff, $12 \%$ were machine operators, also involved in lifting and packing 6\% were machine operators also involved in lifting. 3\% were computer operators, $3 \%$ operated machines and the assembly lines, $3 \%$ performed only lifting, $6 \%$ performed lifting and packing. 


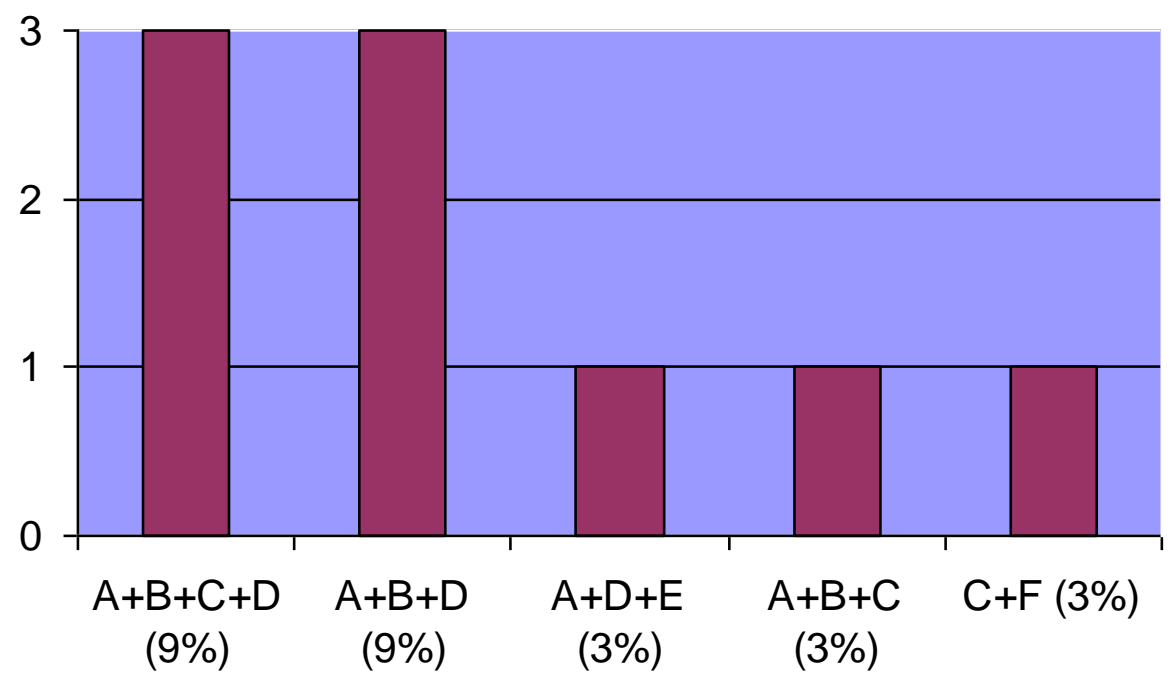

$\square$ No. of Employees in the Warehouse Department

Figure 3 Nature of work of Warehouse staff $A=$ Loading-unloading (lifting \& carrying) $B=$ Frequent bending \& twisting

$C=$ Use of Heat Shrinking \& Cutting machines $D=$ Frequent pushing \& pulling

$E=$ Computer operator (prolonged sitting)

$F=$ Assembly line worker (prolonged standing)

\section{INFERENCE:}

Nature of work of these 9 warehouse staff members was different as they played different occupational roles. The commonest job task was loading and unloading, which involved lifting and carrying, and also frequent bending and lifting.

8 out of the 9 warehouse staff performed loading and unloading, that was $24 \%$ of the total staff.

5 out of 9 warehouse staff, $15 \%$ of the total staff used the heat shrinking and cutting machines.

7 out of 9 warehouse staff, $21 \%$ of the total staff performed bending and twisting.

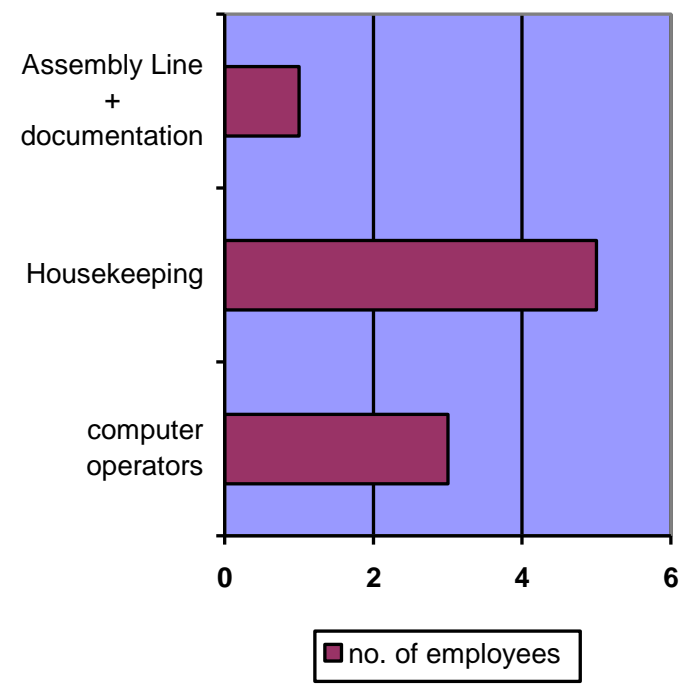

Figure 4: Occupation of Workers in the Manufacturing dept.

\section{INFERENCE:}

Out of the total 33 workers, 9 workers $(27 \%)$ were employed in the Manufacturing dept. Out of these 27\% manufacturing dept staff, $15 \%$ performed housekeeping that involved cleaning, mopping and dusting, 9\% were computer operators, and $3 \%$ operated the assembly lines. 

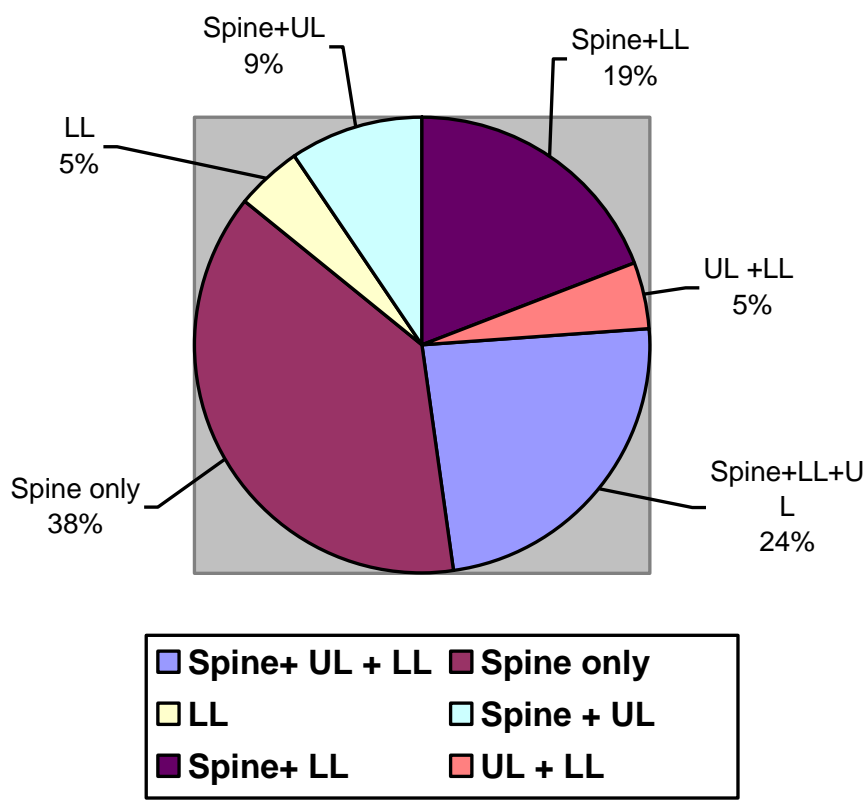

Figure 5 Site of pain for the workers of all departments

\section{INFERENCE:}

Out of the 21 staff $(63 \%)$ that had pain, the commonest site of pain was the spine. Isolated spine pain was the commonest, and was reported in 8 out of 21 individuals (38\%). Spine with upper and lower limb pain was the next most common, and was reported in 5 out of 21 individuals
(24\%). 4 out of 21 individuals had spine and lower limb pain $(19 \%)$, and 2 out of 21 individuals had spine and upper limb pain $(9 \%)$. Least common sites of pain were combined upper and lower limb pain (5\%) and isolated lower limb pain (5\%). No one had reported isolated upper limb pain.

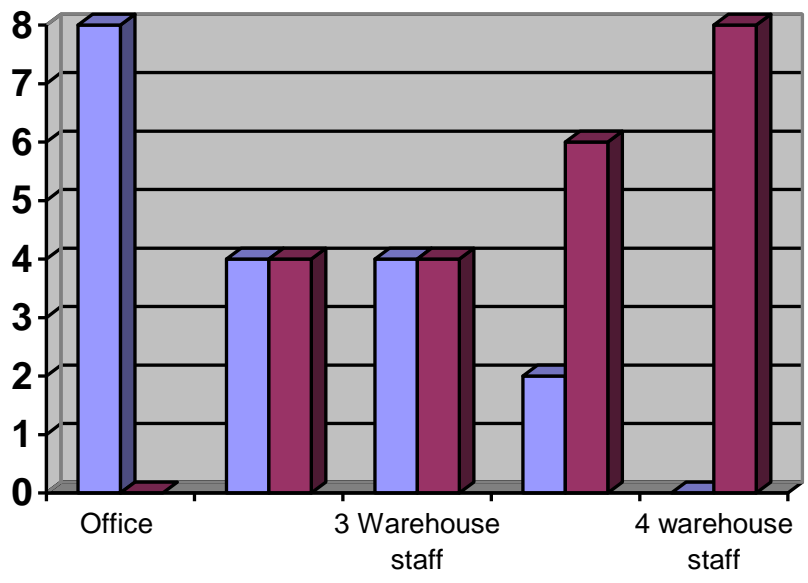

\section{$\square$ Sitting $\square$ Standing}

Figure 6 - Commonly adopted Posture while working

\section{INFERENCE:}

15 out of 33 employees (45\%) consisted of the office staff, of which all had desk jobs. 9 out of $33(27 \%)$ were
Manufacturing staff, and performed both sitting and standing for equal durations. 9 out of $33(27 \%)$ were Warehouse staff, that adopted variable postures. 


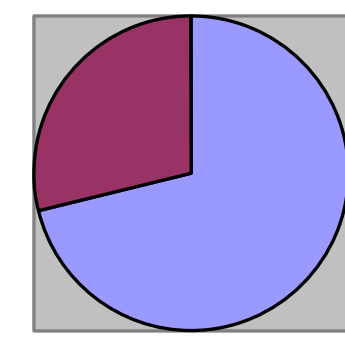

\section{$\square$ Affected $\square$ Not affected}

Figure 7 - Pain interference with normal activities (job, housework, hobbies)

\section{INFERENCE:}

Out of the 21 staff $(63 \%)$ that had pain, 15 staff members reported that their normal activities (job, housework and/or hobbies) were affected by pain, as questioned in the Nordic Musculoskeletal questionnaire.
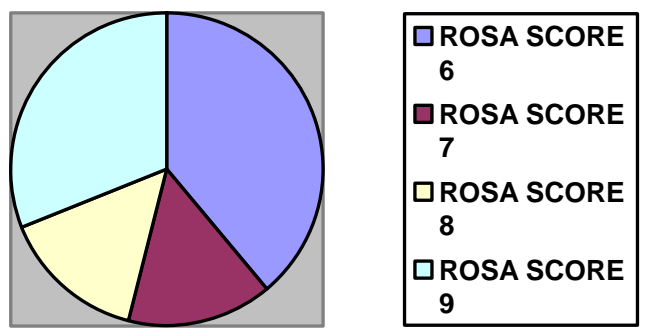

Figure 8 Total ROSA scores in the computer operators

In spite of all the computer operators having ROSA scores greater than 5 which indicates "high risk", only 7 out of the 13 computer operators $(54 \%)$ had pain.

\section{DISCUSSION}

The purpose of the study was to understand the prevalence of common musculoskeletal problems among the workers of the bio-pharmaceutical industry. This study includes the commonest regions involved, the risk factors involved in the development of these problems, the intensity of their pain and the impact it has on their occupation. This study was done based on the data collection done through the questionnaires from the workers of the bio-pharmaceutical industry. This study analyzed data collected from 33 workers. The survey was performed on a one to one interview basis.

Among the 33 workers, 20 were males and 13 were female. All of them were right dominant. Out of the total 33 employees, 15 employees $(45.5 \%)$ were computer operators, and there were 9 employees each in the warehouse and manufacturing departments (27.3\% each). All the employees worked for $81 / 2$ hours per day, six days a week. According to figure 2, out of these $27 \%$ warehouse staff, $12 \%$ were machine operators, also involved in lifting and packing $6 \%$ were machine operators also involved in lifting. 3\% were computer operators, $3 \%$ operated machines and the assembly lines, $3 \%$ performed only lifting, $6 \%$ performed lifting and packing. According to figure 3, out of these $27 \%$ manufacturing dept staff, $15 \%$ performed housekeeping that involves cleaning, mopping and dusting, 9\% were computer operators, and $3 \%$ operated the assembly lines. Based on their job demands, these industrial workers are exposed to various risk factors for the development of workrelated musculoskeletal disorders, such as long hours of awkward or static postures, repetitive activities, forceful movements, frequent bending and twisting motions, loading and unloading of material.

According to figure 1, out of the 33 workers, 21 workers $(63 \%)$ of the workers experience musculoskeletal pain. According to figure 5 , out of the 21 staff $(63 \%)$ that had pain, the commonest site of pain is the spine. Isolated spine pain is the commonest, and was reported in 8 out of 21 individuals $(38 \%)$. Spine with upper and lower limb pain is the next most common, and was reported in 5 out of 21 individuals (24\%). 4 out of 21 individuals had spine and lower limb pain (19\%), and 2 out of 21 individuals had spine and upper limb pain. Least common sites of pain were combined upper and lower limb pain (5\%) and isolated lower limb pain $(5 \%)$.

Globally, $37 \%$ of low back pain is attributed to occupation and work-related 
pain (Punnett et al). Our study is consistent with the previous study (Garg Kapil et al., 2020) that also showed the commonest site of pain to be the spine. ${ }^{[17]}$ Similarly, $57.85 \%$ complained of low back pain, $19 \%$ of the workers complained of neck pain in the Pharmaceutical factory in Dehradun. [7] Even in the study conducted among 43,816 European employees in 34 countries, (Farioli et al.) the prevalence rate of workrelated musculoskeletal back pain ranged from $25.7 \%-63.8 \%$. The same finding was acknowledged in the report of Health and Safety Executive on musculoskeletal disorders in Great Britain in 2014, which revealed the majority of back pain, followed by upper and lower limbs disorders. ${ }^{[18]}$ Schierhout et al. in their study on manufacturing industry in South Africa pointed out that the low back, neck/shoulder, and forearm/wrist regions had high rate of symptoms. ${ }^{[18]}$ Contrasting to our study, Borhany et al. included headache under musculoskeletal pain, and reported headache and back pain to be the two most common musculoskeletal symptoms found in computer operators. ${ }^{[12]}$ In view of our rapid screening methodology, we chose to exclude headaches since isolating the cause of the headache/ migraine to be purely musculoskeletal, would require a physical therapy examination.

The possible risk factors associated with low back pain in this industry were repetitive lifting and carrying, frequent pushing-pulling, bending and twisting performed with awkward postures, as well as prolonged static postures. According to the study by Murtezani, work-related physical factors (such as awkward back postures, high perceived physical load, exposure to whole-body vibration) were strongly associated with the occurrence of sickness absence. Trunk flexion and rotation, with manual material handling has the strongest evidence as a risk factor for low back pain-induced absenteeism. [19] Woods and Buckle stated that main observed risk factors among cleaners were static neck flexion, excessive wrist deviations, frequent arm abduction, back rotation and flexion. Waste collectors in this task had frequent excessive back flexion, back rotation, and repetitive arm abduction, and as well as static elbow extension during bag holding and carrying. Hoozemans $e t$ al. pointed that an increased risk of shoulder and low back injuries are associated with regular push/pull work. ${ }^{[20]}$ High exposure to manual materials handling and whole-body vibration are also risk factors. ${ }^{[21,22]}$

Defining the terms stated as risk factors is imperative for clear understanding. Manual material handling includes lifting, moving, carrying and holding loads. This concept encompasses stresses resulting from work done in transferring objects from one plane to another. Bernard et al. defined lifting as moving or bringing something from a lower level to a higher one. Forceful movements include movement of objects in other ways, such as pulling, pushing, or other efforts. There is strong evidence that low-back disorders are associated with work-related lifting and forceful movements. Bending is defined as flexion of the trunk, usually in the forward or lateral direction. Twisting refers to trunk rotation or torsion. Awkward postures include non-neutral trunk postures (related to bending and twisting). There is a consistent association of work-related awkward postures with low-back disorders. [23]

A systematic review on the association of physical activity with low back pain suggested that biomechanical loading seems to be the most important occupational factor predicting both recurrent low back pain and sick leave attributed to back disorders. Peak lumbar shear forces, cumulative lumbar disc compression, and heavy workload have all been established as risk factors for low back pain. Evidence strongly suggests that the accumulation of loads or frequency of lifts during manual handling is moderately-to-strongly associated with low back pain. The doseresponse relationship between posture of the 
lumbar spine and low back pain is primarily explored by trunk flexion, twisted positions or awkward positions, expressed by duration, extent and percentage of working time. A twofold increased risk was observed in case of the inability to change posture regularly. Evidence strongly suggests that positioning of the lumbar spine in a flexed and/or rotated position is associated with low back pain. There is also a moderate association between prolonged standing (>30 min) and low back pain. ${ }^{[22]}$ A study by US department reported that bending postures are associated with $56 \%$ of low back injuries, twisting or turning are associated with $33 \%$ of injuries. [21] Occupational-related low back disorders are affected by lifting frequency, load moment, trunk lateral velocity, trunk twisting velocity, and trunk sagittal angle. Increases in the magnitude of these factors significantly increased the risk of low back disorders. ${ }^{[24]}$

Sustained static bending or torsion loads on the spine result in creep of spinal segments. In a study on six human cadaveric spines, sustained force was applied in various directions and the displacements of individual motion segments were measured immediately, and after 30 minutes of creep loading (with half of the applied force). The overall flexibility of the spinal segments was in general larger after $30 \mathrm{~min}$ of creep loading. This higher flexibility of the spinal segments may be a risk factor for potential spinal instability or injury. ${ }^{[25]}$ Static work postures include positions where very little movement occurs, along with cramped or inactive postures that cause static loading on the muscles .This includes prolonged standing or sitting and sedentary work. ${ }^{[23]}$ Working in a standing position on a regular basis can cause sore feet, swelling, varicose veins, general muscular fatigue, low back pain and stiffness in the neck and shoulders. Standing effectively reduces the blood supply to the loaded muscles, which accelerates the onset of fatigue and causes pain in the muscles of the legs, back and neck. Prolonged and frequent standing, without some relief by walking, causes blood to pool in the legs and feet. When standing occurs continually over prolonged periods, it can result in inflammation of the veins, which may progress over time to chronic and painful varicose veins. Excessive standing also causes the joints in the spine, hips, knees and feet to become temporarily immobilized or locked, and immobility can later lead to degenerative damage to the tendons and ligaments. ${ }^{[26]}$

During sitting, continuous activity of type I motor units of postural muscles may contribute to the development of fatigue. ${ }^{[23]}$ The static seating position has been shown to lead to an increase in intra-discal pressure, which leads to disc bulges, protrusions and herniation. The ensuing degenerative cascade leads to further changes including ligamentous hypertrophy, facet arthritis and stenosis. Age and hours sitting were found to be significant risk factors for development of disc herniation at the L4-5 level.The findings of this study may also suggest that prolonged sitting of as little as four hours may also be a factor in increasing pressures of the L4-5 disc. ${ }^{[27]}$

A study on low back pain and its relationship with sitting behaviour among sedentary office workers indicates that participants with low back pain or lumbar discomfort exhibit a more static sitting behaviour by demonstrating less micromovements and longer periods of uninterrupted sitting. A reasonable explanation for this observation could be the "fear-avoidance behaviour" implying that regular movements or positional alternation are reduced or avoided due to fear of experiencing pain. Also, participants with chronic pain have a higher level of awareness to pain-free sitting positions and pain provoking movements compared to individuals affected by acute pain. Such a habitual awareness could result in fewer transitions between sitting positions as well as a reduction in small movements, indicating a type of avoidance learning based on the pain history. ${ }^{[16]}$ 
Work-related neck pain is defined as neck pain that is caused or aggravated (or both) by work or the working environment, it is the most common complaint of those who use computers extensively at their workplace. Computer use for more than 4-6 hours was the most important predictor of work related neck pain. Factors such as awkward postures, repetitive work and aggravation of previous pain episodes are also reported as contributing factors. Other work related factors such as perception about breaks, posture, and height of the screen were reported as independent determinants of work related neck pain among desk job workers. ${ }^{[28]}$ Various studies from India reported association of poor or awkward sitting posture at the work place with work related neck pain. Workers working with closely placed keyboard and computer screen were at double the risk. Less time duration of breaks in working hours as perceived by the worker was reported as important reason for work related neck pain. ${ }^{[29]}$ Poor perception of breaks during working hours along with work place related factors like poor posture, height of monitor screen, distance between mouse \& edge of the table, distance between key board \&edge of the desk were identified as independent determinants of work related neck pain. Significant association were found between work related neck pain and higher age, education below graduation, duration of employment, bad posture, mental stress and job pressure. ${ }^{[28]}$

In a study of neck pain among the support staff an Indian tertiary care center, $37 \%$ of workers reported neck pain in the preceding 3 months. Female gender, improper posture, jobs requiring repetitive movements, perception of decreased job control, high body mass index and psychosocial stress were identified as the significant risk factors. ${ }^{[30]}$ In computer professionals, working is related to increasing hours of computer use and incomplete work rest cycle. A prevalence study of neck pain in Indian computer workers reported that $55 \%$ of the people of age group 20 to 50 years have mild and moderate neck pain. This study suggested that sustained passive loading of the various structures of the cervical spine (such as facet, discs and ligaments) in functional sitting postures may provoke a local tissue reaction possibly causing pain. ${ }^{[31]}$

Evidence suggested almost double the risk for developing neck pain in people who spend $95 \%$ of their day or more sitting at work .Physical workstation design and task demands, such as duration of computer use, frequency of breaks, method of keyboard operation, and position of computer monitors, type and use of input devices are associated with work-related neck pain. The slumped forward posture with associated neck flexion is exaggerated when people use notebook and subnotebook computers, compared to desktop computers, and the viewing distances related to using the smaller computers is diminished, thereby worsening posture.

Frequently sitting for a long time is associated with twice the chance of having work-related neck pain. Work-related neck pain is about twice as likely for those sitting with the head in a flexed position. Increased neck flexion angles are associated with increased upper trapezius muscle activity and with neck and shoulder discomfort in office workers. ${ }^{[32]}$

Interventions at the individual level and organizational level are required for the prevention of work related musculoskeletal disorders. The workers can be specifically trained for health and performance related fitness components tailored to their job demands. Pause exercises in between long hours of work, and warm-up exercises before intense activities can be taught as secondary prevention measures. Preemployment screening and functional capacity evaluation will determine if an individual has the capacity to fulfil the job demands of the job profile. ${ }^{[8]}$ Bohr found that a participatory approach, in which workers were instructed how to adjust aspects of their own office, was the most effective in improving the workstation, 
compared to a traditional lecture-based training approach. Participatory approaches allow workers to receive feedback from instructors and have been shown to be beneficial in improving training performance. If the right type of feedback is administered in the right way and at the right time, workers can then apply this feedback to the task in question in order to improve their performance the next time the task is performed. If workers could be trained to perform their own ROSA assessments in an online training module, then the initial screening process would be much quicker. ${ }^{[33]}$ Sustained pressure under the buttocks due to prolonged, uninterrupted sitting could be reduced by varying posture by means of regular pelvis rotations. In this manner, sufficient metabolic balance of various musculoskeletal structures can be supported, including a reduction of ischaemic effects due to prolonged static sitting. ${ }^{[34]}$

\section{CONCLUSION}

The above study identified a high prevalence of work related musculoskeletal disorders among the workers of the Biopharmaceutical industry. The results showed that $63 \%$ of the workers were working with musculoskeletal pain. The most common site of pain was the spine, followed by pain in the spine with both upper and lower extremities. All of the computer workers had ROSA scores greater than 5 which indicates "high risk". All the workers were exposed to ergonomic risk factors such as frequent bending, twisting, repetitive loading and unloading, prolonged sitting, and lifting heavy loads. The workers worked for prolonged periods with inadequate breaks, maintaining their awkward static postures which were a major risk factor for work related back pain.

Considering these results and the high prevalence of work related musculoskeletal disorders, it is imperative to create awareness and recommend the necessary ergonomic advice, along with posture correction and preventive exercises, which may help in minimizing the risk of work related musculoskeletal disorders.

Conflict of Interest: The authors report no conflict of interest in this work.

\section{ACKNOWLEDGEMENTS}

The authors would like to thank all of our study volunteers and the management of Shah Brother's Industry for cooperating with us in carrying out the study, as without them it would have been impossible to complete this study.

\section{Source of Funding: None}

\section{REFERENCES}

1. Yasobant S, Rajkumar P. Work-related musculoskeletal disorders among health care professionals: A cross-sectional assessment of risk factors in a tertiary hospital, India. Indian J Occup Environ Med. 2014 May-Aug; 18(2): 75-81.

2. Yasobant S, Mohanty S. Musculoskeletal disorders as a public health concern in India: A call for action. Physiother- J Indian Assoc Physiother. 2018; 12: 46-17.

3. Pradeepkumar H, Sakthivel G, Shankar S. Prevalence of work related musculoskeletal disorders among occupational bus drivers of Karnataka, South India. Work. 2020; 66(1):73-84.

4. Shankar S, Kumar R, Mohankumar P et al. Prevalence of Work-related Musculoskeletal Injuries Among South Indian Hand Screenprinting Workers. Work. 2017; 58(2):163172.

5. Vieira E, Costa B. Risk Factors for WorkRelated Musculoskeletal Disorders: A Systematic Review of Recent Longitudinal Studies. Am Jour Ind Med. 2009; 53(3): 285-323.

6. Atheer F, Nekhilan A, Anfal M et al. Workrelated musculoskeletal disorders among clinical laboratory workers. Avicenna J Med. 2020 Jan-Mar; 10(1): 29-34.

7. Zutshi A, Warikoo D, Bhatt $\mathrm{S}$ et al. Work related musculoskeletal disorders and associated risk factors among workers in a pharmaceutical factory: A survey study. Int J Cur Res. 2017 Oct; 9 (10): 59227-59230.

8. Mhatre B. Physiotherapeutic perspective in industrial health. In: Bellare B, Rajan P, 
Pandit U. Textbook of prevention practice and community physiotherapy. New Delhi: Jaypee Brothers Medical Publishers, 2018.p. 190-199.

9. Campbell R, Janko M, Hacker R. Hand-arm vibration syndrome: A rarely seen diagnosis. J Vasc Surg Cases Innov Tech. 2017 Apr 25; 3(2):60-62.

10. Occupational safety and health administration. United States Department of Labour. Ergonomics-Overview [Internet]. Available from: https://www.osha.gov/ergonomics

11. Iqbal Z, Alghadir A. Cumulative trauma disorders: A review. J Back Musculoskelet Rehab. 2017 Aug 3; 30(4):663-666.

12. Borhany T, Shahid E. Musculoskeletal problems in frequent computer and internet users. J Family Med Prim Care. 2018 MarApr; 7(2): 337-339.

13. Wærsted $M$, Hanvold $T$, Veiersted $K$. Computer work and musculoskeletal disorders of the neck and upper extremity: A systematic review. BMC Musculoskelet Disord. 2010; 11: 79.

14. Muthukumar A, Mohanraj $\mathrm{K}$ et al. Association of work related risk factors on the development of the neck and upper extremity pain among adult and middleaged population - A survey based analysis. Int J Res Pharma Sci. 2020 Sept; 11 (3): 588-595.

15. J Crawford. The Nordic Musculoskeletal Questionnaire. Occ Med. 2007; 57 (4): 300301.

16. Sonnea M, Andrews D. The Rapid Office Strain Assessment (ROSA): Validity of online worker self-assessments and the relationship to worker discomfort. Occ Ergo. 2012; 10:83-101.

17. Kuijer $P$, Molen V, Frings-Dresen $M$. Evidence-based exposure criteria for workrelated musculoskeletal disorders as a tool to assess physical job demands. Work. 2012; 41 Suppl 1:3795-7.

18. Choobineh A, Daneshmandi H. Prevalence of Work-related Musculoskeletal Symptoms among Iranian Workforce and Job Groups. Int J Prev Med. 2016; 7: 130.

19. Murtezani A, Hundozi H. Low back pain predict sickness absence among power plant workers. Indian J Occup Environ Med. 2010 Aug; 14(2): 49-53.

20. Ziaei M, Choobineh A. Individual, physical, and organizational risk factors for musculoskeletal disorders among municipality solid waste collectors in Shiraz, Iran. Ind Health. 2018 Jul; 56(4): 308-319.

21. Ozguler A, Leclerc A. Individual and occupational determinants of low back pain according to various definitions of low back pain. Jour Epidem comm health. 2000; 54 (3): 215-220.

22. Heneweer H, Staes F. Physical activity and low back pain: a systematic review of recent literature. Eur Spine J. 2011 Jun; 20(6): 826-845.

23. Hermans V. Research on work-related low back disorders. Eur Agency Safety Health Work. 2000.

24. Marras W, Lavender S, Leurgans S et al. Biomechanical risk factors for occupationally related low back disorders. Ergon. 1995 Feb; 38(2):377-410.

25. Busscher I, Dieen J, Veen A. The effects of creep and recovery on the in vitro biomechanical characteristics of human multi-level thoracolumbar spinal segments. Clincal Biomech. 2011 June; 26 (5): 431-534.

26. Canadian Centre for Occupational Health \& Safety. Government of Canada. Working in a standing position- Basic information [Internet]. Available from: https://www.ccohs.ca/oshanswers/ergonomi cs/standing/standing_basic.html

27. Billy G, Lemieux S. Lumbar Disc Changes Associated with Prolonged Sitting. March 2014; 6 (9): 790-795.

28. Chakraborty S, Sinha D. A Study on Work Related Neck Pain among Bank Employees in Kolkata, India. Int $\mathbf{J}$ contemp med Res. 2020 June; 7 (6).

29. Darivemula S, Goswami K. Work-related Neck Pain among Desk Job Workers of Tertiary Care Hospital in New Delhi, India: Burden and Determinants. Indian $\mathbf{J}$ Community Med. 2016 Jan-Mar; 41(1): 5054.

30. Kanagalakshmi V, Muliyil D. Prevalence and risk factors for neck pain among support staff of tertiary care centre. Indian J Comm Health. 2018 Oct-Dec; 30 (4).

31. Bhalala S. Prevalence of Neck Pain in Computer Workers in Surat City: A Crosssectional Study. Int J Cur Res Review. 2019 Oct; 11 (20).

32. Bart $\mathrm{N}$ Green, A literature review of neck pain associated with computer use: public 
health implications. J Can Chiropr Assoc. 2008 Aug; 52(3): 161-167.

33. Sonne M, Villalta D, Andrews D. Development and evaluation of an office ergonomic risk checklist: ROSA-rapid office strain assessment. Appl Ergon. 2012 Jan; 43(1):98-108.

34. Bontrup C, Taylor W. Low back pain and its relationship with sitting behaviour among sedentary office workers. Appl Ergon. 2019, 81 .

How to cite this article: Shah DA, Shah DA, Lakhani NP. Prevalence of musculoskeletal pain in bio-pharmaceutical industry workers. Int $J$ Health Sci Res. 2021; 11(11): 48-61. DOI: https://doi.org/10.52403/ijhsr.20211106 